\title{
Aerosol absorption measurements at Barrow, Mauna Loa and the south pole
}

\author{
Barry A. Bodhaine \\ NOAA Climate Monitoring and Diagnostics Laboratory, Boulder, Colorado
}

\begin{abstract}
Aerosol absorption ( $\left.\sigma_{\mathrm{ap}}\right)$ has been measured continuously using aethalometers at Barrow, Alaska (1986 to present); Mauna Loa, Hawaii (1990 to present); and south pole, Antarctica (1987-1990). These three stations are part of a network of baseline monitoring stations operated by the Climate Monitoring and Diagnostics Laboratory (CMDL) of the National Oceanic and Atmospheric Administration (NOAA). Condensation nucleus (CN) concentration and multiwavelength aerosol scattering $\left(\sigma_{\mathrm{sp}}\right)$ have also been measured continuously for many years at these stations. Aethalometer measurements are usually reported in terms of atmospheric black carbon aerosol (BC) concentration using the calibration suggested by the manufacturer. Here we deduce the in situ $\sigma_{\mathrm{ap}}(550 \mathrm{~nm})$ from aethalometer measurements by assuming that the aerosol absorption on the aethalometer filter is enhanced by a factor of 1.9 over that in the atmosphere. This is consistent with using $19 \mathrm{~m}^{2} \mathrm{~g}^{-1}$ for the specific absorption of $\mathrm{BC}$ on the aethalometer filter and $10 \mathrm{~m}^{2} \mathrm{~g}^{-1}$ for the in situ specific absorption of $B C$ in the atmosphere (the ratio of the two specific absorptions is 1.9). Although these values of specific absorption may vary significantly for different environments, the ratio might be expected to be relatively constant. The single-scattering albedo, defined by $\omega=\sigma_{\mathrm{sp}} /\left(\sigma_{\mathrm{sp}}+\sigma_{\mathrm{ap}}\right)$, has been estimated from the simultaneous measurements of $\sigma_{\mathrm{ap}}$ and $\sigma_{\mathrm{sp}}$. Furthermore, assuming a $1 / \lambda$ dependence for $\sigma_{\mathrm{ap}}$ in the 450 to 700-nm wavelength region, multiwavelength $\sigma_{\mathrm{sp}}$ measurements allow the estimation of the wavelength dependence of $\omega$. Each station shows a considerable annual cycle in $\sigma_{\mathrm{ap}}, \sigma_{\mathrm{sp}}$, and $\omega$. The maximum in the Barrow annual cycle is caused primarily by the springtime Arctic haze phenomenon; the maximum in the Mauna Loa annual cycle is caused by the springtime Asian dust transport; and the maximum in the south pole annual cycle is caused by late winter transport from southern midlatitudes. It was found that annual mean values are $\sigma_{\mathrm{ap}}$ $=4.1 \times 10^{-7} \mathrm{~m}^{-1}\left(\approx 41 \mathrm{ng} \mathrm{m}^{-3} \mathrm{BC}\right)$ and $\omega=0.96$ for Barrow; $\sigma_{\mathrm{ap}}=5.8 \times 10^{-8} \mathrm{~m}^{-1}\left(\approx 5.8^{\mathrm{ap}}\right.$ $\left.\mathrm{ng} \mathrm{m}^{-3} \mathrm{BC}\right)$ and $\omega=0.97$ for Mauna Loa; and $\sigma_{\mathrm{ap}}=6.5 \times 10^{-9} \mathrm{~m}\left(\approx 0.65 \mathrm{ng} \mathrm{m}^{-3} \mathrm{BC}\right)$ and $\omega=0.97$ for south pole. It was also found that the wavelength dependence of $\omega$ may be important at Barrow and south pole, but not important at Mauna Loa.
\end{abstract}

\section{Introduction}

Aerosol particles suspended in the atmosphere influence the Earth's climate in a direct or indirect manner. Direct effects refer to the interaction of the suspended particles with the radiation field in the atmosphere. Indirect effects refer to the effects of particles on cloud processes, which in turn affect climate. Possible climate forcing by anthropogenic aerosols has been discussed by Charlson et al. [1992] and Kiehl and Briegleb [1993]. Current climate forcing by anthropogenic sulfate is thought to be of comparable magnitude to that by greenhouse gases but is opposite in sign and is caused by aerosol backscattering to space. Because aerosol absorption may also be important, particularly on a local scale, it is important to establish current background values and to assess the possible climatic effects of anthropogenic contributions. Clarke and Charlson [1985] discussed the role of black carbon $(\mathrm{BC})$ aerosol related to the background radiative properties of the atmosphere.

The Climate Monitoring and Diagnostics Laboratory (CMDL) (formerly GMCC) of the National Oceanic and Atmospheric Ad-

Copyright 1995 by the American Geophysical Union.

Paper number 95JD00513.

0148-0227/95/95JD-00513\$05.00 ministration (NOAA) operates baseline atmospheric monitoring stations at Barrow, Alaska (BRW); Mauna Loa, Hawaii (MLO); American Samoa (SMO); and Amundsen-Scott Station, south pole (SPO). The mission of this program is to conduct measurements of atmospheric quantities that may influence the Earth's climate, to identify both natural and anthropogenic sources and sinks of these quantities, and to understand their possible effects on climate.

The CMDL baseline aerosol monitoring program consists of the continuous measurement of condensation nucleus (CN) concentration and aerosol scattering coefficient $\left(\sigma_{\mathrm{sp}}\right)$ at BRW, MLO, SMO, and SPO [Bodhaine, 1983]. The Importance of Carbon Particles in the Atmosphere Workshop, held in Boulder, Colorado, stressed the importance of absorbing particles and recommended that aerosol absorption coefficient $\left(\sigma_{\mathrm{ap}}\right)$ be measured at the CMDL observatories [Bodhaine and Winchester, 1981]. Continuous $\sigma$ measurements were initiated at BRW in 1986, MLO in 1990, and SPO in 1987 [Bodhaine et al., 1989, 1992; Hansen et al., 1988]. Short-term BC experiments at these stations were reported by Rosen et al. [1981], Clarke and Charlson [1985], Bodhaine et al. [1988], Bodhaine [1989a, b], and Hansen et al. [1989].

The purpose of this report is to summarize the $\sigma_{\text {ap }}$ measurements made at the CMDL observatories and to present initial 
analyses for these stations. Simultaneous measurements of $\sigma_{\mathrm{cp}}$ and $\sigma_{\mathrm{ap}}$ allow the calculation of single-scattering albedo, $\omega=$ $\sigma_{\mathrm{sp}} /\left(\sigma_{\mathrm{sp}}+\sigma_{\mathrm{ap}}\right)$, an important parameter in climate modeling.

\section{Instrumentation}

\section{CN Counters}

$\mathrm{CN}$ concentrations were originally measured at CMDL stations using General Electric (GE) automatic CN counters [Bodhaine, 1983]. The GE counter uses an expansion chamber to produce a cloud at a water supersaturation of about $300 \%$. The density of the cloud is measured by optical means and converted to nuclei concentration through a calibration derived from daily comparisons with a Pollak CN counter [Pollak and Metnieks, 1960; Bodhaine and Murphy, 1980]. Thermo Systems Incorporated (TSI) CN counters (model 3760) were installed at BRW in March 1990, MLO in May 1988, and SPO in January 1989. The TSI counter is a continuous flow instrument that uses butyl alcohol as its working fluid to produce a cloud of alcohol droplets by directly cooling the airstream. The droplets are then counted by a single-particle counter to give the absolute concentration. The operation of the TSI counters was described by Thermo Systems Incorporated (TSI) [1987]. CN concentration data are used primarily to screen the $\sigma_{\mathrm{sp}}$ and $\sigma_{\mathrm{ap}}$ data for local pollution effects. A complete $\mathrm{CN}$ climatology is available for each station from the author.

\section{Nephelometer}

The $\sigma_{\text {ap }}$ has been measured at the CMDL baseline stations using four-wavelength nephelometers with optics similar to that described by Ahlquist and Charlson [1969]. A continuous flow of air through the instrument is illuminated by a quartz-halogen lamp, and scattered light is detected by a photomultiplier (PMT). A rotating filter wheel in front of the PMT allows the detection of light at the nominal 450-, 550-, 700-, and 850-nm wavelengths. The instrument automatically switches between ambient air and filtered air and does a real-time subtraction to eliminate the instrument background (including the Rayleigh scattering of air). This instrument, described in detail by Bodhaine [1982], is capable of measuring $\sigma_{\mathrm{sp}}$ values as low as about $10^{-7} \mathrm{~m}^{-1}$, about $1 \%$ of the scattering by air molecules.

Multiwavelength nephelometer data are often expressed as a power function of wavelength $(\lambda)$ in the form $\sigma_{\mathrm{sp}}=\mathrm{K}_{1} \lambda^{-\alpha}$, where $\mathrm{K}_{1}$ is a constant and $\alpha$ is known as the Angstrom exponent. Aerosol size distribution information may be derived from multiwavelength nephelometer measurements [Thielke et al., 1972] by examining $\alpha$. In general, a large $\alpha$ implies smaller particles, and a small $\alpha$ implies larger particles.

\section{Aethalometer}

The light-absorbing component of the aerosol is measured at CMDL baseline stations with aethalometers manufactured by Magee Scientific [Hansen et al., 1982]. The aethalometer measures the real-time attenuation of light transmitted through particles that accumulate on a quartz-fiber filter. A vacuum pump draws air through the instrument so that particles continuously accumulate on the filter while being illuminated by a lamp. Light transmission through the filter is sensed by two photocells: one through a sample spot where aerosol accumulates and another through a reference portion of the filter where no aerosol accumulates. The intensities of the two light beams are measured as a function of time, and the instantaneous attenuation of the sample beam may be recovered by taking the ratio of the sample beam to the reference beam and differencing the time series. The reference beam compensates for any variations in lamp brightness or drift in the electronics. Alternating periods of lamp-on and lamp-off allow for subtraction of detector dark currents. The instrument has an incandescent light source and a broadband detector, the spectral response for elemental carbon particles peaks at approximately $830 \mathrm{~nm}$ (A.D.A. Hansen, personal communication, 1991). Our instruments operate at a flow rate of about 11 standard liters per minute (slpm), and aerosol is accumulated on a circular spot with an area of about $0.95 \mathrm{~cm}^{2}$.

The stability of the aethalometer optics allows detection of changes in transmitted light intensity of 1 part in $10^{4}$, corresponding to a $\sigma_{\text {ap }}$ noise level of about $1.5 \times 10^{-8} \mathrm{~m}^{-1}$ (about $1.5 \mathrm{ng} \mathrm{m}^{-3} \mathrm{BC}$ ) for a 1-hour collection period. Instrument control and data acquisition are performed by dedicated laptop computers, and all data are available in real time and stored on floppy disks with a time resolution of 1 hour, with the exception of BRW where 10-min data are stored.

$\mathrm{BC}$ is usually the dominant absorber in the atmospheric aerosol [Rosen et al., 1978]. Hematite $\left(\mathrm{Fe}_{2} \mathrm{O}_{3}\right)$, a constituent of desert dust, is the only other strong absorber found commonly in the atmospheric aerosol; however, about 200 times as much hematite (mass) as BC is needed for equivalent absorption. Schnell et al. [1994] studied the relative contributions of dust and BC to $\sigma_{\mathrm{ap}}$ at MLO. They found a maximum of about $20 \%$ absorption contributed by dust during a large dust storm recorded at MLO. Similar results were found even in dust storms in the former Soviet Central Asia [Hansen et al., 1993]. However, the contribution to absorption by dust at MLO is usually negligible.

Since the aethalometer by its very nature measures aerosol absorption on the filter, $\sigma_{\text {ap }}$ may be inferred directly from light absorption on the filter by using a suitable calibration constant. In this work, $\sigma_{\mathrm{ap}}$ (per meter) was calculated using the formula

$$
\sigma_{\mathrm{ap}}(550 \mathrm{~nm})=-\frac{1}{1.9} \frac{\mathrm{A} \ln \left(\mathrm{I}_{2} / \mathrm{I}_{1}\right)}{\mathrm{Q}\left(\mathrm{t}_{2}-\mathrm{t}_{1}\right)},
$$

where $I_{1}$ and $I_{2}$ are the ratios of the intensities of the sample beam to the reference beam at times $t_{1}$ and $t_{2}$ (seconds); $Q$ (cubic meters per second) is the volume flow rate of air through the filter, A (square meters) is the area of the spot on the filter, and the constant 1.9 is the enhancement of aerosol absorption for the aerosol embedded in the quartz-fiber filter matrix over that in the atmosphere, with the particular illumination used in the instrument. For simplicity the correction for detector dark current is not shown here in equation (1).

The aethalometer manufacturer provides a calibration factor that relates the attenuation of the light beam through the filter to the $\mathrm{BC}$ mass loading on the filter. To provide this calibration, $\mathrm{BC}$ loadings on filters collected in various locations were determined by measuring the $\mathrm{CO}_{2}$ evolved in a temperatureprogrammed furnace. The manufacturer recommends that the $\mathrm{BC}$ concentration (grams per cubic meter) be calculated from the formula

$$
\mathrm{BC}=-\frac{1}{19} \frac{\mathrm{A} \ln \left(\mathrm{I}_{2} / \mathrm{I}_{1}\right)}{\mathrm{Q}\left(\mathrm{t}_{2}-\mathrm{t}_{1}\right)}
$$

However, equation (2) requires an assumption not needed in equation (1), that the value of the aethalometer specific absorp- 
tion $\left(19 \mathrm{~m}^{2} \mathrm{~g}^{-1}\right)$ does not vary for different sources, size distributions, and mixtures of BC. Liousse et al. [1993] suggest a range of $5-20 \mathrm{~m}^{2} \mathrm{~g}^{-1}$ for the aethalometer specific absorption, which could introduce an error in estimates of $B C$. Here we wish to estimate $\sigma_{\mathrm{ap}}$ directly, and as noted above, the aethalometer actually measures aerosol absorption on the filter substrate (not BC).

Traditionally, estimating $\sigma_{\mathrm{ap}}$ from aethalometer measurements has been a two-step process. First, $\mathrm{BC}$ concentration is calculated using equation 2 . Second, $\sigma_{\mathrm{ap}}$ is calculated using the equation $\sigma_{a p}=\left(S_{a}\right)(B C)$, where $S_{a}$ is the specific absorption of $B C$ suspended in the atmosphere. Commonly used values for $S_{a}$ are of the order of $10 \mathrm{~m}^{2} \mathrm{~g}^{-1}$ at a wavelength of $550 \mathrm{~nm}$ [Gerber, 1982; Clarke and Charlson, 1985; Bodhaine et al., 1992]. However, since the aethalometer measures $\sigma_{\mathrm{ap}}$ directly, the intermediate step of calculating $\mathrm{BC}$ is unnecessary. Rather, $\sigma_{\mathrm{ap}}(550 \mathrm{~nm})$ can be calculated directly from aethalometer data using equation (1).

The constant 1.9 in equation (1) is consistent with the ratio of an aethalometer specific absorption of $19 \mathrm{~m}^{2} \mathrm{~g}^{-1}$ on the filter substrate and a specific absorption of $10 \mathrm{~m}^{2} \mathrm{~g}^{-1}$ at $550 \mathrm{~nm}$ for $\mathrm{BC}$ aerosol suspended in the atmosphere. Since the intermediate step of calculating $\mathrm{BC}$ has been eliminated, possible errors in the assumed value of 19 in equation (2) are avoided. It is likely that the value 1.9 in equation (1) remains fairly constant over a wide range of environmental conditions because in one sense it represents the ratio of the aethalometer instrumental specific absorption to the in situ atmospheric specific absorption. Although each might be expected to vary under different environmental conditions, they would be expected to vary similarly. Alternatively, the aethalometer enhances the apparent aerosol absorption by a factor of 1.9 (at $550 \mathrm{~nm}$ ) because the particles are embedded in the filter substrate matrix. This factor of 1.9 relationship may also be inferred from the comparisons of Rosen et al. [1978], Lin et al. [1973], and Sadler et al., [1981], as discussed by Bodhaine et al. [1992]. Further investigations are needed to verify that the ratio of the two specific absorptions is indeed fairly constant for different environments and that 1.9 is a suitable estimate for this ratio.

In this work, $\sigma_{\mathrm{ap}}(550 \mathrm{~nm})$ was calculated from equation (1), and under the above assumptions, $\sigma_{\mathrm{ap}}(550 \mathrm{~nm})=1 \times 10^{-8} \mathrm{~m}^{-1}$ is approximately equivalent to $\mathrm{BC}=1 \mathrm{ng} \mathrm{m}$. This provides a convenient estimate of $\mathrm{BC}$ but does not take into account the contribution of absorbers other than BC (such as in a strong dust event at MLO).

Because $\sigma_{\mathrm{ap}}$ is approximately inversely proportional to $\lambda$ for BC aerosol over the visible band [van de Hulst, 1957; Jennings and Pinnick, 1980; Gerber, 1982; Horvath, 1993; Liousse et al., 1994; Dobbins et al., 1994], it is possible to specify $S_{a}$ as a function of wavelength and therefore to estimate $\sigma_{\mathrm{ap}}$ as a function of wavelength from the aethalometer data. Replacing the constant 1.9 by $C(\lambda)$ in the denominator of equation (1), and assuming that $C(550 \mathrm{~nm})=1.9$, we have for the purposes of this report that $\mathrm{C}(450 \mathrm{~nm})=1.5, \mathrm{C}(550 \mathrm{~nm})=1.9$, and $\mathrm{C}(700 \mathrm{~nm})=2.4$. Note that $\sigma_{\mathrm{ap}}$ decreases with increasing wavelength. Finally, $\omega$ as a function of wavelength can be calculated from the corresponding multiwavelength $\sigma_{\mathrm{ap}}$ and $\sigma_{\mathrm{sp}}$ data. All $\sigma_{\mathrm{ap}}$ and $\sigma_{\mathrm{sp}}$ data are presented in volume units at the effective altitude of the particular observatory.

To examine the variation of $\omega$ with wavelength, consider that $\sigma_{\mathrm{sp}}=\mathrm{K}_{1} \lambda^{-a}$ and $\sigma_{\mathrm{ap}}=\mathrm{K}_{2} \lambda^{-1}$, where $\mathrm{K}_{1}$ and $\mathrm{K}_{2}$ are constants. Then $\omega=\mathrm{K}_{1} /\left(\mathrm{K}_{1}+\mathrm{K}_{2} \lambda^{(a-1)}\right)$. Obviously, $\omega$ is independent of $\lambda$ if $\alpha=1$. However, $\omega$ will vary somewhat with $\lambda$ for typical atmospheric values of $\alpha$. For example, typical background values of $\alpha$ at BRW are about 1.5 [Bodhaine, 1989a], typical values at MLO are about 0-2 depending on the presence of Asian dust [Bodhaine et al., 1992], and typical values at SPO are about 1.3-1.8 [Bodhaine et al., 1986].

\section{Data Analysis}

\section{Data Screening Techniques}

To construct a data set consisting of screened background values of $\sigma_{\mathrm{zp}}, \sigma_{\mathrm{ap}}, \alpha$, and $\omega$, it was necessary to merge the $\sigma_{\mathrm{up}}, \sigma_{\mathrm{ap}}$, wind direction (WD), and wind speed (WS) data sets to guarantee that background $\sigma_{\mathrm{sp}}$ and $\sigma_{\mathrm{ap}}$ were averaged over exactly the same time periods. Hourly average data sets were used as starting points for all subsequent averages. First, an hour of $\sigma_{\mathrm{sp}}$ data was accepted if data for 450,550 , and $700 \mathrm{~nm}$ were not missing. Only these three wavelengths of data were chosen because the data for $850 \mathrm{~nm}$ tend to be missing more often than the others. For Mauna Loa, because of a diurnal wind flow cycle causing exposure to local pollution sources, only nighttime data were accepted (nighttime data were defined as 2200-0800 Hawaii standard time (HST)). Next, if local pollution was suspected, that hour of data was excluded. Wind data for that hour were checked and that hour of data was excluded if WD was not from the station clean-air sector or if WS was $<0.5 \mathrm{~m} \mathrm{~s}^{-1}$. The cleanair sectors used in this study for the three stations are given in Table 1. Finally, if the hourly data value for $\sigma_{\text {ap }}$ was not missing, then $\sigma_{\mathrm{ap}}, \sigma_{\mathrm{ap}}, \alpha$, and $\omega$ for that hour were included in 2-day mean calculations; $\alpha$ was calculated using the formula

$$
\alpha=-\frac{1}{2}\left\{\frac{\log \left[\sigma_{\Phi p}(450) / \sigma_{\Phi}(550)\right]}{\log (450 / 550)}+\frac{\log \left[\sigma_{\Phi}(550) / \sigma_{\varphi p}(700)\right]}{\log (550 / 700)}\right\},
$$

where equation (3) is simply the average of the two independent values of $\alpha$ calculated for the intervals $450-550$ and 550-700 $\mathrm{nm}$, respectively, $\omega$ was calculated from the formula $\omega=\sigma_{\mathrm{sp}} /\left(\sigma_{\mathrm{sp}}\right.$ $\left.+\sigma_{\mathrm{ap}}\right)$. Thus $\sigma_{\mathrm{sp}}$ and $\sigma_{\mathrm{ap}}$ were handled in identical manners for exactly the same time periods, ensuring the most accurate estimates of $\alpha$ and $\omega$. Note that in cases when the various data sets had significant missing data, the merge process could result in small numbers of values available to calculate a given 2-day mean.

Two-day means were chosen to assemble a basic set of independent data points because hourly aerosol data at BRW are autocorrelated out to about 35-50 hours [Bodhaine and Dutton, 1993]. Therefore a 2-day mean is a convenient choice, and the same criteria were used for all three stations in this study. Once a set of 2-day mean data was constructed, monthly medians and

Table 1. Clean Air Sampling Sectors for BRW, MLO, and SPO

\begin{tabular}{cc}
\hline Station & Clean Air Sector \\
\hline BRW & $0^{\circ}-130^{\circ}$ \\
MLO & $90^{\circ}-270^{\circ}$ \\
SPO & $330^{\circ}-110^{\circ}$ \\
\hline
\end{tabular}

BRW, Barrow, Alaska; MLO, Mauna Loa, Hawaii; SPO, south pole, Antarctica. 


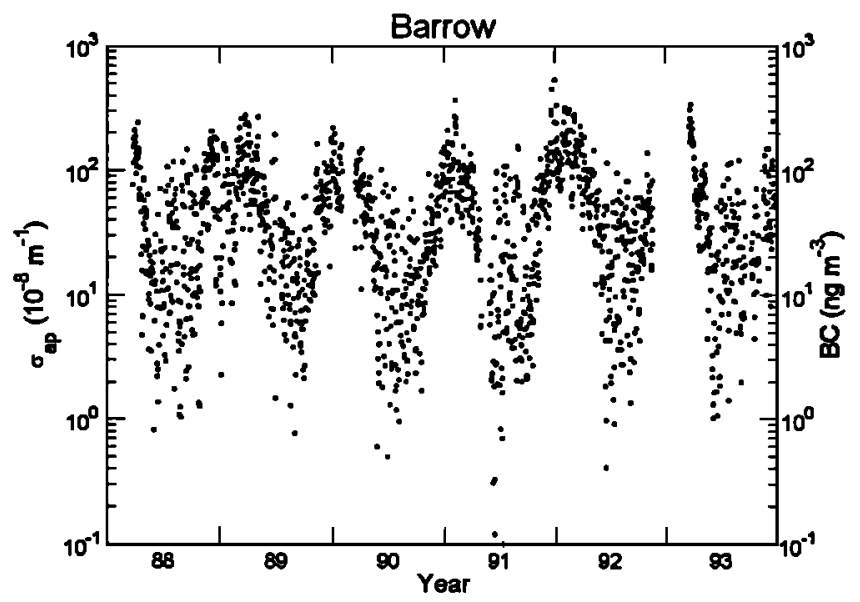

Figure 1. Daily mean black carbon (BC) aerosol concentration at Barrow, Alaska, for 1988-1993. No data screening or merging operations were performed.

quartiles for all data sets were calculated in order to study possible annual cycles at the three sites.

\section{Barrow, Alaska}

The Barrow monitoring station was established in 1972 at Point Barrow, the northernmost tip of Alaska. Aerosol measurements were initiated in 1976. This site has been found to be representative of the Arctic region and the springtime phenomenon known as the Arctic haze. The observatory building is located to the east of Barrow village and, with prevailing winds from the ENE, is upwind of local pollution sources about $76 \%$ of the time. A map of the area and a discussion of the influence of local pollution sources were presented by Bodhaine et al. [1981a]. CN and $\sigma_{\mathrm{ap}}$ data for Barrow were presented by Bodhaine [1983], Murphy and Bodhaine [1980b], and Quakenbush and Bodhaine [1986].

An aethalometer was first installed at BRW for ground-based $\sigma_{\text {ep }}$ measurements during the second Arctic Gas and Aerosol Sampling Program (AGASP II) in March-April 1986. Results of this experiment were published in a special issue of the Joumal of Atmospheric Chemistry, vol. 9, pp. 1-397, 1989 [see e.g., Bodhaine et al., 1989].

Daily means of the entire BRW $\sigma_{\mathrm{ap}}$ data set are presented in Figure 1 in order to show the characteristics of the data set before merging and screening were performed. A repeatable annual cycle is evident with a maximum in March-April and a minimum in the late summer. The spring maximum is attributed to Arctic haze, an Arctic-wide phenomenon [Joranger and Ottar, 1984] caused by the long-range transport of anthropogenic pollution generated in the northern midlatitudes. Maximum values for $\sigma_{\mathrm{ap}}$ in the spring are about $3 \times 10^{-6} \mathrm{~m}^{-1}(\mathrm{BC} \approx 300 \mathrm{ng}$ $\mathrm{m}^{-3}$ ) and minimum values are in the vicinity of $10^{-8} \mathrm{~m}^{-1}(\mathrm{BC}$ $\approx 1 \mathrm{ng} \mathrm{m}^{-3}$ ). Occasional clean values may be as low as $\sigma_{\text {ap }}=2$ $\times 10^{-9} \mathrm{~m}^{-1}\left(\mathrm{BC}=0.2 \mathrm{ng} \mathrm{m}^{-3}\right)$, comparable to clean conditions at MLO and SPO.

Monthly medians of the BRW $\sigma_{\mathrm{ap}}, \sigma_{\mathrm{ap}}$, and $\omega$ data at $550 \mathrm{~nm}$ are shown in Figure 2. The top and bottom bars show quartiles. Note that these monthly medians were constructed from hourly data according to the screening criteria discussed in the previous section, so that $\sigma_{\mathrm{sp}}$ and $\sigma_{\mathrm{ap}}$ were averaged over exactly the same time periods. In so doing, however, missing data in the various data sets can reduce the number of data points used to form the various medians and quartiles.
Referring to the $\sigma_{\mathrm{sp}}$ data in Figure 2, the annual cycle due to the Arctic haze phenomenon is apparent, with springtime monthly medians exceeding $2 \times 10^{-5} \mathrm{~m}^{-1}$ and summertime monthly medians of about $10^{-6} \mathrm{~m}^{-1}$. The $\sigma_{\mathrm{ap}}$ data show a similar annual cycle with a maximum of about $2 \times 10^{-6} \mathrm{~m}^{-1}(\mathrm{BC} \approx$ $\left.200 \mathrm{ng} \mathrm{m}^{-3}\right)$ and a minimum of about $7 \times 10^{-8} \mathrm{~m}^{-1}(\mathrm{BC}=7 \mathrm{ng}$ $\mathrm{m}^{-3}$ ). Because of the slightly stronger annual cycle in $\sigma_{\mathrm{ap}}$ a similar annual cycle is seen in $\omega$ with a minimum in springtime, suggesting that enhanced concentrations of $\mathrm{BC}$ coincide with Arctic haze events. Springtime $\omega$ monthly values are as low as about 0.9 , indicating significant absorption, whereas summer values are as high as $\mathbf{0 . 9 8}$. Note that the July 1988 data point for $\omega$ has an upper quartile exceeding 1 . The corresponding median for $\sigma_{\text {ap }}$ is close to zero with an upper quartile of about $10^{-7} \mathrm{~m}^{-1}$. These values of $\sigma_{\mathrm{ap}}$ could not be plotted on the graph but impossible values can occur in the calculations because of noisy data during clean conditions. However, the monthly median and upper quartile of $\sigma_{\mathrm{ep}}$ for July 1988 probably give reasonable limits on its actual value.

The monthly medians of the 1989 data shown in Figure 2 are presented in Table 2. To save space, the year with the best data recovery was chosen for each station. The peak of the Arctic haze event occurs in March, showing $\sigma_{\mathrm{sp}}=1.47 \times 10^{-5} \mathrm{~m}^{-1}$ and $\sigma_{\mathrm{ap}}=1.31 \times 10^{-6}\left(\mathrm{BC} \approx 131 \mathrm{ng} \mathrm{m}^{-3}\right)$. The corresponding $\alpha=$ 1.29 (maximum for the year) and $\omega=0.928$ (minimum for the year) suggest smaller and more absorbing particles, probably combustion aerosol, during that month. It should be noted that an $\omega$ value shown in the table is the median of the 2-day means for that month. This value can be slightly different than a value of $\omega$ calculated directly from the monthly medians of $\sigma_{\mathrm{ap}}$ and $\sigma_{\mathrm{ap}}$.
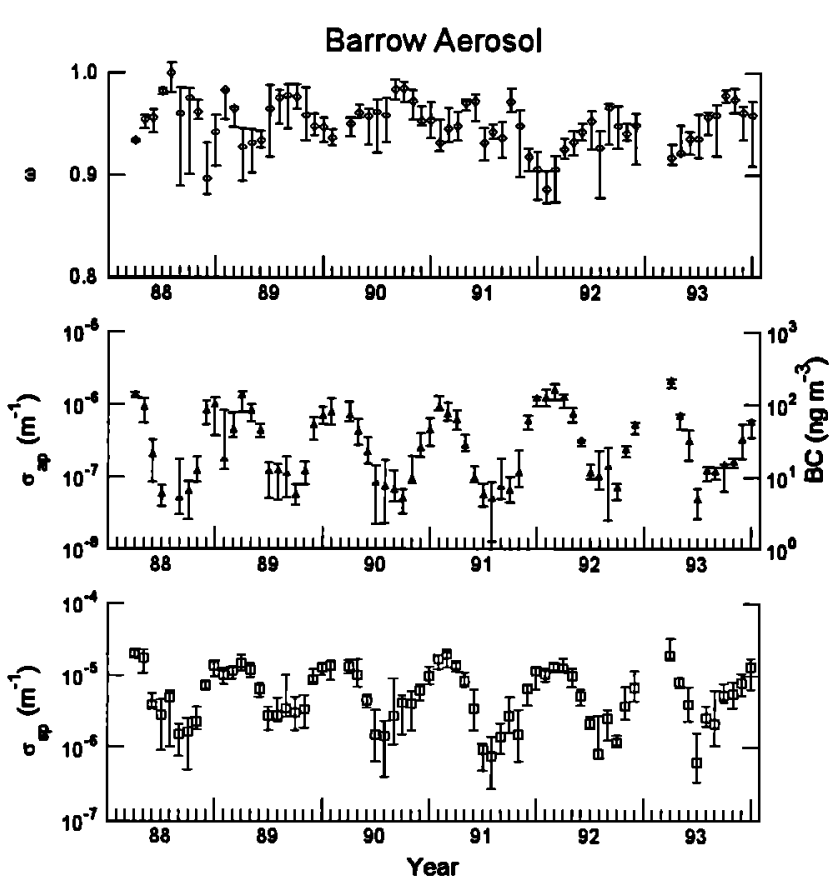

Figure 2. Monthly medians of $\sigma_{\mathrm{sp}}(550 \mathrm{~nm}), \sigma_{\mathrm{ap}}$, and $\omega$ at Barrow, Alaska, for 1988-1993. The upper and lower bars show the quartile points, respectively, for each month. Monthly medians were calculated from 2-day means according to the screening and merging criteria described in the text. The single-scattering albedo was calculated from $\omega=\sigma_{\mathrm{sp}} /\left(\sigma_{\mathrm{sp}}+\sigma_{\mathrm{ep}}\right)$ for each 2-day mean value. 
Table 2. Monthly Medians of $\sigma_{\mathrm{sp}}(550 \mathrm{~nm})\left(10^{-6} \mathrm{~m}^{-1}\right)$, $\alpha, \sigma_{\mathrm{ap}}(550 \mathrm{~nm})\left(10^{-8} \mathrm{~m}^{-1}\right)$, and $\omega$ for 1989 at BRW

\begin{tabular}{lccrc}
\hline Month & $\sigma_{\text {sp }}$ & $\alpha$ & $\sigma_{\text {sp }}$ & $\omega$ \\
\hline Jan. & 10.2 & 1.02 & 17.6 & 0.983 \\
Feb. & 11.6 & 1.04 & 43.6 & 0.965 \\
March & 14.7 & 1.29 & 131.0 & 0.928 \\
April & 11.8 & 1.26 & 79.6 & 0.932 \\
May & 6.48 & 1.62 & 42.8 & 0.934 \\
June & 2.74 & 1.84 & 11.7 & 0.965 \\
July & 2.76 & 0.67 & 12.0 & 0.976 \\
Aug. & 3.48 & 0.59 & 11.0 & 0.978 \\
Sept. & 3.04 & 0.16 & 5.6 & 0.977 \\
Oct. & 3.36 & 0.59 & 11.6 & 0.959 \\
Nov. & 8.51 & 0.95 & 51.2 & 0.948 \\
Dec. & 13.0 & 1.22 & 69.3 & 0.947 \\
Mean & 7.64 & 1.02 & 40.6 & 0.958 \\
\hline
\end{tabular}

\section{Mauna Loa, Hawaii}

MLO is located at an altitude of $3.4 \mathrm{~km}$ on the north slope of Mauna Loa mountain, on the island of Hawaii. This site is often representative of the midtroposphere in that region of the Pacific Ocean, particularly during the nighttime downslope wind conditions [Mendonca, 1969]. Ordinarily, winds with a southerly component occur during the night and are representative of the background midtroposphere, and winds with a northerly component occur during the day but may be contaminated by local island processes. $\mathrm{CN}$ and $\sigma_{\mathrm{sp}}$ data for MLO were presented by Bodhaine and Mendonca [1974], Bodhaine [1978, 1981, 1983], and Massey et al. [1987].

The routine aerosol monitoring program at MLO was initiated in 1974 and consists of the measurement of $\mathrm{CN}$ concentration and $\sigma_{\mathrm{sp}}$. Continuous $\sigma_{\mathrm{ap}}$ measurements were initiated at MLO in April 1990 using an aethalometer. Bodhaine et al. [1992] presented the first year of continuous $\sigma_{\text {ap }}$ measurements at MLO. Measurements of $\sigma_{\text {ap }}$ were made in 1982 by Clarke and Charlson [1985].

The well-known annual cycle in aerosol concentrations at MLO was discussed by Bodhaine et al. [1981b]; the springtime maximum is caused by the long-range transport of dust from Asian deserts [Darzi and Winchester, 1982; Shaw, 1980]. Trajectories calculated backward from MLO [Miller, 1981; Harris and $K a h l, 1990]$ show frequent long-range transport from Asia during winter and spring. The aerosol maximum in April and May at MLO occurs when strong westerly flow coincides with dust storms over Asian deserts [Merrill et al., 1989].

Daily means of the entire MLO $\sigma_{\text {ap }}$ data set are presented in Figure 3. No merging or screening has been done, other than to include only nighttime data (2200-0800 HST). A repeatable annual cycle is evident with a maximum in April-May and a minimum in winter. As mentioned above, the springtime maximum is caused by the long-range transport of desert dust from Asia, suggesting that anthropogenic materials originating in the source regions are transported as well. Maximum values for $\sigma_{\text {ap }}$ in the spring are about $10^{-6} \mathrm{~m}^{-1}\left(\mathrm{BC} \approx 100 \mathrm{ng} \mathrm{m}^{-3}\right)$ and minimum values are in the vicinity of $2 \times 10^{-8} \mathrm{~m}^{-1}\left(\mathrm{BC} \approx 2 \mathrm{ng} \mathrm{m} \mathrm{m}^{-3}\right.$ ). Occasional clean values may be less than $10^{-9} \mathrm{~m}^{-1}(\mathrm{BC}=0.1$ $\mathrm{ng} \mathrm{m}^{-3}$ ), comparable to the cleanest conditions at SPO.

Monthly medians of the MLO $\sigma_{\mathrm{sp}}, \sigma_{\mathrm{ap}}$, and $\omega$ data at $550 \mathrm{~nm}$ are shown in Figure 4. The top and bottom bars show quartiles.
Again, note that missing data in the various data sets can reduce the number of data points used to form the various medians and quartiles. Referring to Figure 4, the $\sigma_{\mathrm{sp}}$ data show an annual cycle with a maximum in April-May, caused by the long-range transport of Asian desert dust. The maximum monthly median of $\sigma_{\mathrm{pp}}$ is about $6 \times 10^{-6} \mathrm{~m}^{-1}$ and the minimum is about $6 \times$ $10^{-7} \mathrm{~m}^{-1}$, giving an annual variation of about an order of magnitude. On the other hand, $\sigma_{\text {ap }}$ varies from a maximum of about 3 $\times 10^{-7} \mathrm{~m}^{-1}\left(\mathrm{BC}=30 \mathrm{ng} \mathrm{m} \mathrm{m}^{-3}\right)$ to a minimum of about $10^{-8}$ $\mathrm{m}^{-1}\left(\mathrm{BC}=1 \mathrm{ng} \mathrm{m}^{-3}\right)$. This produces an annual cycle in $\omega$ that is in phase with those of $\sigma_{\mathrm{sp}}$ and $\sigma_{\mathrm{ap}}$ and varies between about 0.91 and 0.99. Evidently, $\mathrm{BC}$ of anthropogenic origin is transported from Asia along with the dust during the springtime season. Aerosol episodes at MLO were examined on a daily basis [Bodhaine et al., 1992] and it was found that large values of $\sigma_{\mathrm{sp}}$ and $\mathrm{BC}$ usually coincide but can occur separately during strong transport from Asia. As shown by Schnell et al. [1994], absorption by dust can account for as much as $20 \%$ of the total absorption during the strongest dust episode. Therefore estimates of $\mathrm{BC}$ during these episodes could be significantly in error.

The monthly medians for 1992 were chosen as the best year for data recovery and are presented in Table 3. The peak of the Asian dust event of $\sigma_{\mathrm{sp}}=4.01 \times 10^{-6} \mathrm{~m}^{-1}$ occurred in April, the peak of $\sigma_{\text {ap }}=2.83 \times 10^{-7}\left(\mathrm{BC} \approx 28.3 \mathrm{ng} \mathrm{m}^{-3}\right)$ occurred in March, and the minimum of $\omega=0.943$ occurred in March, indicating that the annual cycles of $\sigma_{\mathrm{sp}}$ and $\sigma_{\mathrm{ap}}$ may have been slightly out of phase. Examination of Figure 4 shows that $\sigma_{\mathrm{sp}}$ and $\sigma_{\mathrm{ap}}$ were in phase for two of the years and slightly out of phase for two of the years; $\omega$ shows a maximum of about 0.99 in December and a minimum of about 0.94 in March.

\section{South Pole, Antarctica}

The Amundsen-Scott Station was established at the geographic south pole for the International Geophysical Year in 1956; CMDL began measurements in 1974. The CMDL program is located upwind from the camp in the Clean Air Facility, constructed by the National Science Foundation on the greater polar plateau at about $2.84 \mathrm{~km}$ (mean sea level (msl)). The prevailing winds are from about grid $\mathrm{NE}$ and are from the clean-air sector about $95 \%$ of the time. Bodhaine et al. [1986] presented a map of the site and a general description of sampling conditions.

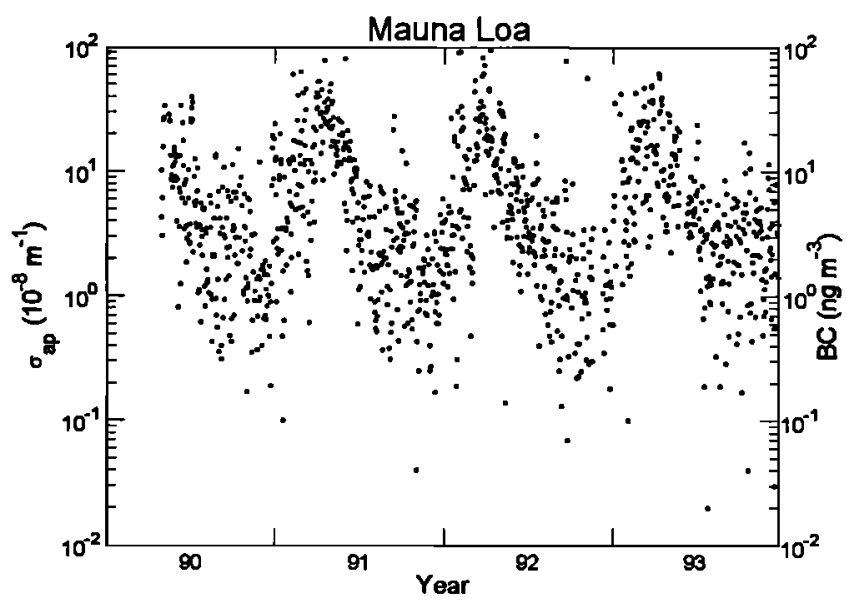

Figure 3. Daily mean BC aerosol concentration at Mauna Loa, Hawaii, for 1990-1993. No data screening or merging operations were performed. 

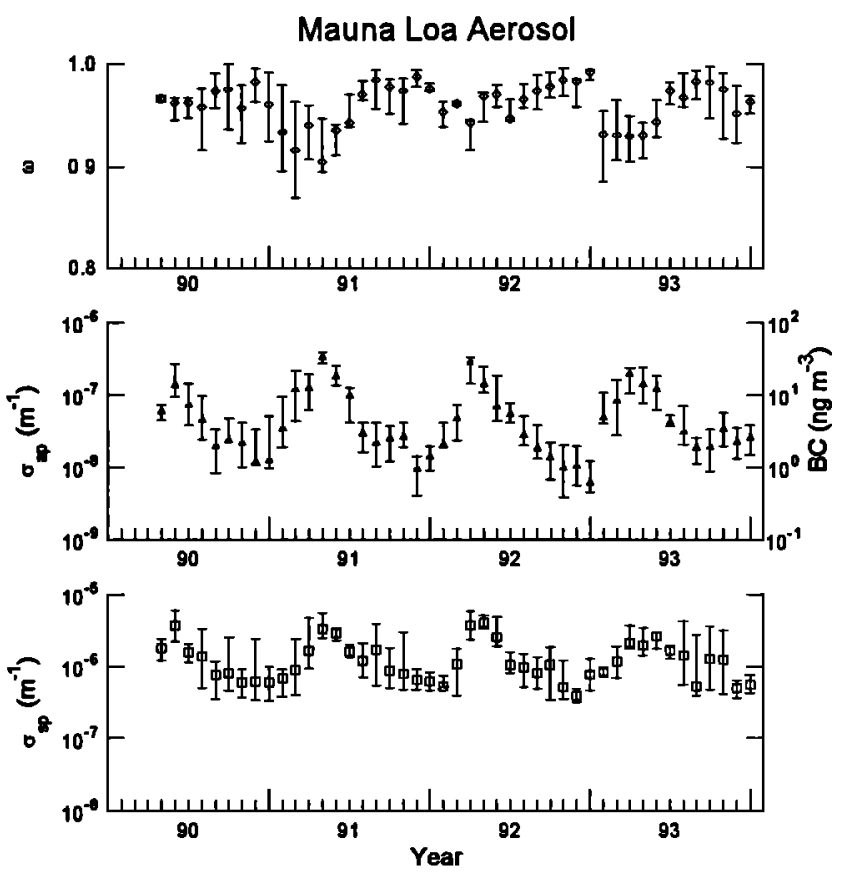

Figure 4. Monthly medians of $\sigma_{\mathrm{sp}}(550 \mathrm{~nm}), \sigma_{\mathrm{ap}}$, and $\omega$ at Mauna Loa Hawaii, for 1990-1993. The upper and lower bars show the quartile points, respectively, for each month. Monthly medians were calculated from 2-day means according to the screening and merging criteria described in the text. The singlescattering albedo was calculated from $\omega=\sigma_{\mathrm{sp}} /\left(\sigma_{\mathrm{sp}}+\sigma_{\mathrm{ap}}\right)$ for each 2-day mean value.

The routine aerosol measurement program began in 1974 with the installation of a Pollak CN counter and a GE automatic CN counter. A four-wavelength nephelometer was installed at SPO in 1979. CN and $\sigma_{\text {sp }}$ data for SPO were presented by Bodhaine and Murphy [1980], Murphy and Bodhaine [1980a], Bodhaine and Bortniak [1981], Bodhaine et al. [1986, 1987], Bodhaine and Shanahan [1990], and Bodhaine and Harris [1992]. The first $\sigma_{\text {ap }}$ measurements were made during 1987 and presented by Hansen et al. [1988], and measurements were continued through December 1990.

Table 3. Monthly Medians of $\sigma_{\mathrm{sp}}(550 \mathrm{~nm})\left(10^{-6} \mathrm{~m}^{-1}\right)$, $\alpha, \sigma_{\mathrm{ap}}(550 \mathrm{~nm})\left(10^{-8} \mathrm{~m}^{-1}\right)$, and $\omega$ for 1992 at $\mathrm{MLO}$

\begin{tabular}{lllrl}
\hline Month & $\sigma_{\text {sp }}$ & $\alpha$ & $\sigma_{\text {ep }}$ & $\omega$ \\
\hline Jan. & 0.525 & 1.77 & 1.99 & 0.954 \\
Feb. & 1.06 & 2.24 & 4.78 & 0.962 \\
March & 3.69 & 1.15 & 28.30 & 0.943 \\
April & 4.01 & 1.29 & 14.00 & 0.969 \\
May & 2.52 & 0.58 & 6.92 & 0.971 \\
June & 1.05 & 0.96 & 5.37 & 0.947 \\
July & 0.947 & 1.26 & 2.80 & 0.966 \\
Aug. & 0.790 & 1.60 & 1.78 & 0.974 \\
Sept. & 1.03 & 1.81 & 1.35 & 0.978 \\
Oct. & 0.507 & 1.64 & 0.97 & 0.985 \\
Nov. & 0.388 & 1.46 & 1.02 & 0.983 \\
Dec. & 0.762 & 1.50 & 0.59 & 0.992 \\
Mean & 1.44 & 1.44 & 5.82 & 0.969 \\
\hline
\end{tabular}

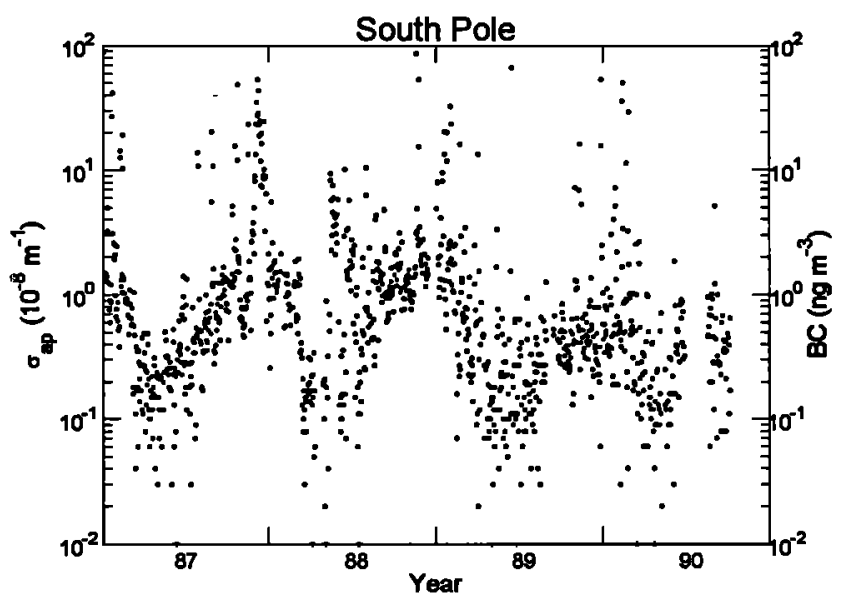

Figure 5. Daily mean BC aerosol concentration at AmundsenScott Station, south pole, for 1987-1990. No data screening or merging operations were performed.

Daily means of the entire SPO $\sigma_{\mathrm{ap}}$ data set are presented in Figure 5. Again, no merging or screening has been done. A repeatable annual cycle is evident with a maximum in the austral summer and a minimum in early winter. Maximum values for $\sigma_{\mathrm{ap}}$ in the summer are about $5 \times 10^{-7} \mathrm{~m}^{-1}\left(\mathrm{BC}=50 \mathrm{ng} \mathrm{m}^{-3}\right)$ and minimum values are in the vicinity of $2 \times 10^{-10} \mathrm{~m}^{-1}$ (BC $\approx$ $0.02 \mathrm{ng} \mathrm{m}^{-3}$ ). Occasional clean values may be of the order of $10^{-10} \mathrm{~m}^{-1}\left(\mathrm{BC} \approx 0.01 \mathrm{ng} \mathrm{m}^{-3}\right)$.

Monthly medians of the 1987 SPO $\sigma_{\text {sp, }}, \sigma_{\text {ap }}$, and $\omega$ data at 550 $\mathrm{nm}$ are shown in Figure 6 . The upper and lower error bars show quartiles. Because of missing data in the various data sets the
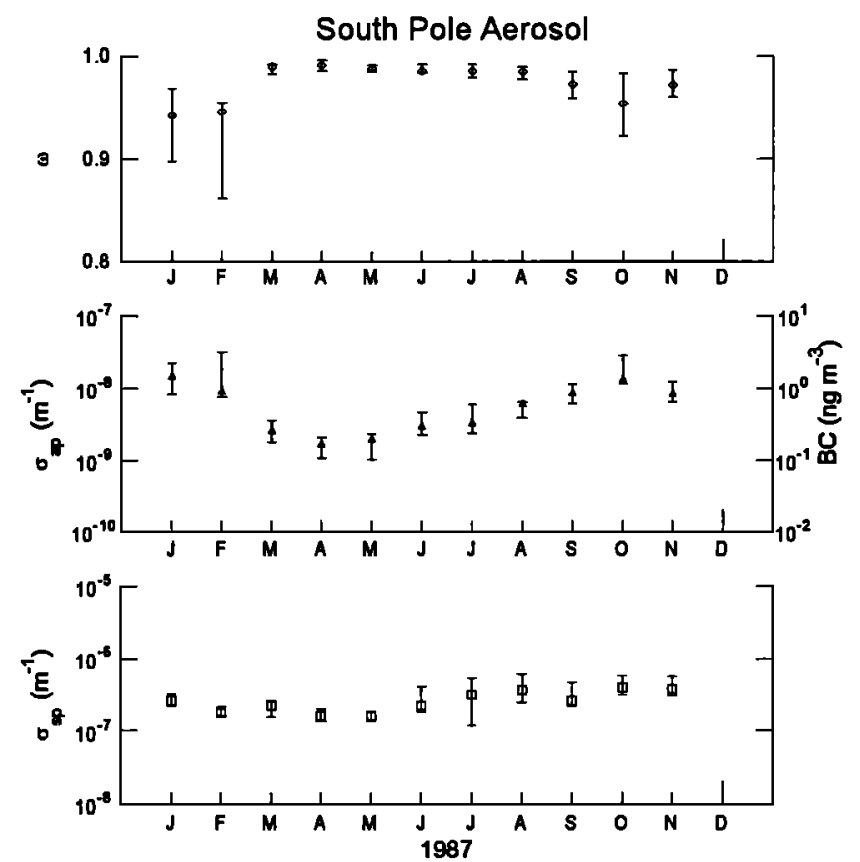

Figure 6. Monthly medians of $\sigma_{\mathrm{sp}}(550 \mathrm{~nm}), \sigma_{\mathrm{ap}}$, and $\omega$ at Amundsen-Scott Station, South Pole, for 1987. The upper and lower bars show the quartile points, respectively, for each month. Monthly medians were calculated from 2-day means according to the screening and merging criteria described in the text. The single-scattering albedo was calculated from $\omega=$ $\sigma_{\mathrm{sp}} /\left(\sigma_{\mathrm{sp}}+\sigma_{\mathrm{sp}}\right)$ for each 2 -day mean value. 
Table 4. Monthly Medians of $\sigma_{\mathrm{sp}}(550 \mathrm{~nm})\left(10^{-6} \mathrm{~m}^{-1}\right)$, $\alpha, \sigma_{\mathrm{ap}}(550 \mathrm{~nm})\left(10^{-8} \mathrm{~m}^{-1}\right)$, and $\omega$ for 1987 at SPO

\begin{tabular}{lllll}
\hline Month & $\sigma_{\text {ap }}$ & $\alpha$ & $\sigma_{\text {ap }}$ & $\omega$ \\
\hline Jan. & 0.255 & 2.89 & 1.46 & 0.942 \\
Feb. & 0.180 & 3.19 & 0.90 & 0.946 \\
March & 0.222 & 2.38 & 0.25 & 0.990 \\
April & 0.161 & 2.27 & 0.17 & 0.991 \\
May & 0.158 & 2.33 & 0.20 & 0.988 \\
June & 0.219 & 1.96 & 0.30 & 0.986 \\
July & 0.314 & 1.75 & 0.32 & 0.986 \\
Aug. & 0.362 & 1.44 & 0.60 & 0.985 \\
Sept. & 0.256 & 1.54 & 0.86 & 0.973 \\
Oct. & 0.393 & 1.56 & 1.29 & 0.954 \\
Nov. & 0.376 & 2.05 & 0.82 & 0.972 \\
Mean & 0.263 & 2.12 & 0.65 & 0.974 \\
\hline
\end{tabular}

merging procedure resulted in a limited number of data points in 1988-1990. Therefore monthly medians (and quartiles) are shown only for 1987. Referring to Figure 6 , the $\sigma_{\mathrm{sp}}$ data show an annual cycle with a minimum in the late austral summer of about $10^{-7} \mathrm{~m}^{-1}$ and a maximum of about $4 \times 10^{-7} \mathrm{~m}^{-1}$ in the late winter. The maximum has been identified as the long-range midtropospheric transport of sea salt from oceanic areas surrounding the Antarctic continent [Bodhaine et al., 1986, 1987; Parungo et al., 1981; Harris, 1992]. The $\omega$ data in Figure 6 show an annual cycle with a maximum in the winter and a minimum in the summer, suggesting that the sea-salt transport events do not contribute to enhanced concentrations of BC relative to $\sigma_{\mathrm{sp}}$

Table 4 presents the monthly medians for the data shown in Figure 6. As discussed above, the $\sigma_{\mathrm{sp}}$ and $\sigma_{\mathrm{ap}}$ data have somewhat similar annual cycles, but the resulting $\omega$ values have a significant annual cycle with a maximum in the austral winter and a minimum in the summer. Cross correlations were calculated for the data in Table 4. The strongest correlation is between $\mathrm{BC}$ and $\omega(-0.92)$, suggesting that $\mathrm{BC}$ controls $\omega$, because the annual cycle of $B C$ is stronger than that of $\sigma_{\mathrm{sp}}$. The only other significant correlation was between $\sigma_{\mathrm{sp}}$ and $\alpha$ $(-0.62)$. The smallest correlations were between $\alpha$ and $\mathrm{BC}$
(0.14) and $\sigma_{\text {sp }}$ and $\omega(-0.19)$. The smallest value of $\alpha$ occurred as expected during August, the month of strongest sea-salt transport, suggesting larger particles.

\section{Discussion}

One of the goals of this paper is to estimate $\sigma_{\mathrm{ap}}$ and $\omega$ as a function of $\lambda$ at the three stations, using multiwavelength nephelometer data (assuming that $\sigma_{\mathrm{ap}}$ varies as $1 / \lambda$ ). For each station, two months were chosen (from Tables 2, 3, and 4), representative of extremes in the annual cycle of $\omega$ for that station. March and September 1989 were chosen for Barrow, April and December 1992 were chosen for Mauna Loa; and February and August 1987 were chosen for south pole. The results of these calculations are shown in Table 5. The $\sigma_{\mathrm{sp}}(450), \sigma_{\mathrm{sp}}(550)$, $\sigma_{\mathrm{sp}}(700)$, and $\sigma_{\mathrm{ap}}(550)$ values shown in Table 5 are the monthly medians measured for each station/month at the given wavelength. The $\sigma_{\mathrm{ap}}(450)$ and $\sigma_{\mathrm{ep}}(700)$ values were calculated from the $\sigma_{\text {ap }}(550)$ values assuming that $\sigma_{\mathrm{ap}}$ varies as $1 / \lambda ; \alpha_{12}$ and $\alpha_{23}$ were calculated from $\sigma_{\mathrm{sp}}(450)$ and $\sigma_{\mathrm{ap}}(550)$ and from $\sigma_{\mathrm{mp}}(550)$ and $\sigma_{\text {sp }}(700)$, respectively. Finally, $\omega(450), \omega(550)$, and $\omega(700)$ were calculated from the respective values of $\sigma_{\mathrm{ap}}$ and $\sigma_{\mathrm{ap}}$.

It is apparent from Table 5 that $\sigma_{\mathrm{sp}}$ and $\sigma_{\mathrm{ap}}$ vary significantly with wavelength. (Please recall that $\sigma_{\mathrm{sp}}(\lambda)$ was actually measured at 450,550 , and $700 \mathrm{~nm}$, whereas $\sigma_{\mathrm{ap}}(\lambda)$ was measured at $550 \mathrm{~nm}$ and assumed to vary as $1 / \lambda$.) It is interesting to note that the monthly variation of $\sigma_{\mathrm{sp}}(550)$ and $\sigma_{\mathrm{ep}}(550)$ at the quartile points is about the same as the variation of $\sigma_{\mathrm{sp}}$ and $\sigma_{\mathrm{ap}}$ between adjacent wavelengths for all six cases shown in Table 5. This suggests that for monthly estimates of $\sigma_{\mathrm{sp}}$ and $\sigma_{\mathrm{ap}}$, over the wavelength band $450-700 \mathrm{~nm}$, variability with wavelength is not an important consideration at these three sites. The behavior of $\omega(\lambda)$ is interesting in light of the previous discussion (at the end of the aethalometer section); $\omega$ will vary with $\lambda$ only if $\alpha$ differs significantly from 1 , and $\omega$ can either increase or decrease with $\lambda$ depending on whether $\alpha<1$ or $\alpha>1$. For example, $\omega$ for BRW in March increases and then decreases with $\lambda$, because $\alpha_{12}$ $<1$ and $\alpha_{23}>1$. Similarly, $\omega$ for BRW in September simply increases with $\lambda ; \omega$ for MLO does not vary significantly with $\lambda$ because $\alpha$ is close to 1. On the other hand, $\omega$ for SPO in February decreases significantly with wavelength (from 0.96 to 0.90 ) be-

Table 5. Values of $\sigma_{\mathrm{sp}}, \sigma_{\mathrm{ap}}, \omega$, and $\alpha$ at the 450-, 550-, and 700-nm Wavelengths for BRW During March and September 1989, MLO During April and December 1992, and SPO During February and August 1987

\begin{tabular}{|c|c|c|c|c|c|c|c|c|c|c|c|c|}
\hline \multirow{2}{*}{$\begin{array}{l}\text { Station } \\
\text { Year }\end{array}$} & \multirow[b]{2}{*}{ Month } & \multicolumn{3}{|c|}{$\left(10^{-6} \mathrm{~m}^{-1}\right)$} & \multicolumn{3}{|c|}{$\left(10^{-8} \mathrm{~m}^{-1}\right)$} & \multirow[b]{2}{*}{$\omega 450$} & \multirow[b]{2}{*}{$\omega 550$} & \multirow[b]{2}{*}{$\omega 700$} & \multirow[b]{2}{*}{$\alpha_{12}$} & \multirow[b]{2}{*}{$\alpha_{23}$} \\
\hline & & $\sigma_{\mathrm{sp}} 450$ & $\sigma_{\mathrm{sp}} 550$ & $\sigma_{\mathrm{sp}} 700$ & $\sigma_{\mathrm{ep}} 450$ & $\sigma_{\mathrm{ap}} 550$ & $\sigma_{\mathrm{ap}} 700$ & & & & & \\
\hline BRW & March & 16.5 & 14.7 & 9.18 & 160. & 131. & 103. & 0.922 & 0.928 & 0.911 & 0.58 & 1.95 \\
\hline 1989 & Sept. & 2.97 & 3.04 & 2.65 & 6.82 & 5.58 & 4.38 & 0.971 & 0.977 & 0.979 & -0.12 & 0.57 \\
\hline MLO & April & 4.90 & 4.01 & 2.94 & 17.1 & 14.0 & 11.0 & 0.969 & 0.969 & 0.967 & 1.00 & 1.29 \\
\hline 1992 & Dec. & 0.962 & 0.762 & 0.612 & 0.726 & 0.594 & 0.467 & 0.992 & 0.992 & 0.992 & 1.16 & 0.91 \\
\hline SPO & Feb. & 0.304 & 0.180 & 0.0725 & 1.10 & 0.901 & 0.708 & 0.960 & 0.946 & 0.900 & 2.61 & 3.77 \\
\hline 1987 & Aug. & 0.461 & 0.362 & 0.250 & 0.736 & 0.602 & 0.473 & 0.986 & 0.985 & 0.983 & 1.20 & 1.53 \\
\hline
\end{tabular}

The value of $\alpha_{12}$ was calculated from $\sigma_{\mathrm{sp}}(450)$ and $\sigma_{\mathrm{sp}}(550) ; \alpha_{23}$ was calculated from $\sigma_{\mathrm{sp}}(550)$ and $\sigma_{\mathrm{sp}}(700)$. Note that the units of $\sigma_{\mathrm{ap}}$ are expressed such that the values shown in the table for $\sigma_{\mathrm{ap}}(550)$ may be interpreted approximately as BC (nanograms per cubic meter). 
cause $\alpha>1$. In spite of these considerations, however, the monthly variation of $\omega(550)$ at the quartile points (for all three stations) is larger than the variation of $\omega$ between adjacent wavelengths, suggesting that the variation of $\omega$ with wavelength is not an important consideration (over $450-700 \mathrm{~nm}$ ) for monthly estimates. This is because the monthly variabilities of $\sigma_{\mathrm{sp}}$ and $\sigma_{\mathrm{ap}}$ tend to be relatively large; however, wavelength may be important when considering variability on other timescales.

It is difficult to predict the climatic effects of the aerosols discussed in this report without a comprehensive model. Indeed, one of the purposes of this report is to provide aerosol parameters for incorporation into climate models. However, a few general comments can be made. As discussed by Ackerman [1988], two important parameters in aerosol climate models are $\omega$ and the albedo of the underlying surface. An $\omega=0.85$ appears to be a critical value, such that $\omega<0.85$ would warm the system and $\omega>0.85$ would cool the system. Furthermore, a high surface albedo (bright surface, such as snow) will enhance warming, and a low albedo (dark surface, such as ocean) will enhance cooling. In all cases, weakly absorbing aerosol (large $\omega$ ) will produce a cooling. Strongly absorbing aerosol will produce warming for a bright surface and cooling for a dark surface, depending on the values used in the model for $\omega$ and surface albedo. The surface albedo is high for BRW and SPO (ice and snow, about 0.85) and low for MLO (ocean, about 0.06). During summer in the Arctic, breakup of the icepack near BRW results in a lower surface albedo that could reduce a warming effect.

All of the monthly median values of $\omega$ reported here for all three sites are above 0.9 , well up in the range that would be expected to produce cooling, regardless of the surface albedo. However, short-term measurements near Barrow have suggested heating rates during Arctic haze events as high as $0.16-0.25 \mathrm{~K}$ $\mathrm{d}^{-1}$ [Valero and Ackerman, 1986]. Thus significant warming can occur in the Arctic on a regional basis and over timescales of several days when lower values of $\omega$ occur. Long-term average values of $\omega$ for MLO reported by Clarke and Charlson [1985] and Bodhaine et al. [1992] are also in the range that would be expected to produce cooling. However, Bodhaine et al. [1992] showed daily average events of $\omega=0.70$ and 0.85 during February 1991. The author has personally observed Asian dust events at MLO that nearly obscure the Sun. Evidently, warming events may be occasionally possible at MLO but have not been documented. No estimates of $\omega$ have previously been made for SPO. It is clear from the data presented here that the aerosol climatic effect at SPO would be a cooling but would be small.

Acknowledgments. I wish to thank the staff of the CMDL observatories for their diligent efforts at operating and maintaining the aerosol instrumentation. I also thank Helene Cachier, Catherine Liousse, Tony Hansen, Gerard Jennings, and Russell Schnell for their helpful comments conceming this manuscript.

\section{References}

Ackerman, T. P., Aerosols in climate modeling, in Aerosols and Climate, edited by P. V. Hobbs and M. P. McCormick, pp. 335-348, A. Deepak, Hampton, Va., 1988.

Ahlquist, N. C., and R. J. Charlson, Measurement of the wavelength dependence of atmospheric extinction due to scatter, Atmos. Environ., 3, 551-564, 1969.

Bodhaine, B. A., The Mauna Loa four wavelength nephelometer: Instrument details and three years of observations, NOAA Tech. Rep. ERL 396-ARL 5, 39 pp., Air Resour. Lab./GMCC, Boulder, Colo., 1978.
Bodhaine, B. A., Nuclei monitoring at baseline sites: Barrow, Alaska; Mauna Loa, Hawaii; American Samoa; and South Pole, in Atmospheric Aerosols and Nuclei, edited by A. F. Roddy and T. C. O'Conner, pp. 244-248, Galway University Press, Galway, Ireland, 1981.

Bodhaine, B. A., The GMCC four-wavelength nephelometer, in Light Absorption by Aerosol Particles, edited by H. E. Gerber and E. E. Hindman, pp. 149-168, Spectrum, Hampton, Va., 1982.

Bodhaine, B. A., Aerosol measurements at four background sites, J. Geophys. Res., 88, 10,753-10,768, 1983.

Bodhaine, B. A., Barrow surface aerosol: 1976-1986, Atmos. Environ., 23, 2357-2369, 1989a.

Bodhaine, B. A., South Pole aerosol measurements, Antarct. J. U. S., 16, 233-235, 1989b.

Bodhaine, B. A., and J. C. Bortniak, Four wavelength nephelometer measurements at the South Pole, Geophys. Res. Lett., 8, 539-542, 1981.

Bodhaine, B. A., and E. G. Dutton, A long-term decrease in Arctic haze at Barrow, Alaska, Geophys. Res. Lett., 20, 947-950, 1993.

Bodhaine, B. A., and J. M. Harris, Aerosol measurements at the South Pole during 1987, NOAA Data Rep. ERL CMDL-9, 120 pp., Clim. Monit. and Diagn. Lab., Boulder, Colo., 1992.

Bodhaine, B. A., and B. G. Mendonca, Preliminary four wavelength nephelometer measurements at Mauna Loa Observatory, Geophys. Res. Lett., 1, 119-122, 1974.

Bodhaine, B. A., and M. E. Murphy, Calibration of an automatic condensation nuclei counter at the South Pole, J. Aerosol Sci., 11, 305-312, 1980.

Bodhaine, B. A., and M. K. Shanahan, Condensation nucleus and aerosol scattering extinction measurements at the South Pole observatory: 1979-1988, NOAA Data Rep. ERL CMDL-1, 148 pp., Clim. Monit. and Diagn. Lab., Boulder, Colo., 1990.

Bodhaine, B. A., and J. W. Winchester, Importance of Carbon Particles in the Atmosphere, Report of a Workshop, Air Resour. Lab., Boulder, Colo., 1981.

Bodhaine, B. A., J. M. Harris, and G. A. Herbert, Aerosol light scattering and condensation nuclei measurements at Barrow, Alaska, Atmos. Environ., 15, 1375-1389, 1981 a.

Bodhaine, B. A., B. G. Mendonca,, J. M. Harris, and J. M. Miller, Seasonal variations in aerosols and atmospheric transmission at Mauna Loa Observatory, J. Geophys. Res., 86, 7395-7398, 1981b.

Bodhaine, B. A., J. J. Deluisi, J. M. Harris, P. Houmere, and S. Bauman, Aerosol measurements at the South Pole, Tellus, 38(B), 223-235, 1986.

Bodhaine, B. A., J. J. DeLuisi, J. M. Harris, P. Houmere, and S. Bauman, PDXE analysis of South Pole aerosol, Nucl. Instr. Method., 22(B), 241-247, 1987.

Bodhaine, B. A., E. G. Dutton, J. J. DeLuisi, J. M. Harris, G. E. Shaw, A. D. A. Hansen, and T. Novakov, South Pole aerosol measurements during 1987, in Atmospheric Aerosols and $\mathrm{Nu}$ cleation, edited by P. E. Wagner and G. Vali, pp. 225-228, Springer-Verlag, New York, 1988.

Bodhaine, B. A., E. G. Dutton, J. J. Deluisi, G. A. Herbert, G. E. Shaw, and A. D. A. Hansen, Surface aerosol measurements at Barrow during AGASP II, J. Atmos. Chem., 9, 213-224, 1989.

Bodhaine, B. A., J. M. Harris, J. A. Ogren, and D. J. Hofmann, Aerosol optical properties at Mauna Loa Observatory: Longrange transport from Kuwait?, Geophys. Res. Lett., 19, 581-584, 1992.

Charlson, R. J., S. E. Schwartz, J. M. Hales, R. D. Cess, J. A. Coakley Jr., J. E. Hansen, and D. J. Hofmann, Climate forcing by anthropogenic aerosols, Science, 255, 423-430, 1992.

Clarke, A. D., and R. J. Charlson, Radiative properties of the background aerosol: Absorptive component of extinction, Science, 229, 263-265, 1985. 
Darzi, M., and J. W. Winchester, Aerosol characteristics at Mauna Loa Observatory, Hawaii, after East Asian dust storm episodes, J. Geophys. Res., 87, 1251-1258, 1982.

Dobbins, R. A., G. W. Mulholland, and N. P Bryner, Comparison of a fractal smoke optics model with light extinction measurements, Atmos. Environ., 28, 889-897, 1994.

Gerber, H. E., Absorption of light by atmospheric aerosol particles: Review of instrumentation and measurements, in Light Absorption by Aerosol Particles, edited by H. E. Gerber and E. E. Hindman, pp. 21-53, Spectrum, Hampton, Va., 1982.

Hansen, A. D. A., H. Rosen, and T. Novakov, Real-time measurement of the absorption coefficient of aerosol particles, Appl. Opt., 21, 3060-3062, 1982.

Hansen, A. D. A., B. A. Bodhaine, E. G. Dutton, and R. C. Schnell, Aerosol black carbon measurements at the South Pole: Initial results, 1986-1987, Geophys. Res. Lett., 15, 1193-1196, 1988.

Hansen, A. D. A., T. J. Conway, L. P. Steele, B. A. Bodhaine, K. W. Thoning, P. Tans, and T. Novakov, Correlations among combustion effluent species at Barrow, Alaska: Aerosol black carbon, carbon dioxide, and methane, J. Atmos. Chem., 9, 283-299, 1989.

Hansen, A. D. A., V. N. Kapustin, V. M. Kopeikin, D. A. Gillette, and B. A. Bodhaine, Optical absorption by aerosol black carbon and dust in a desert region of central Asia, Atmos. Environ., 27(A), 2527-2531, 1993.

Harris, J. M., An analysis of 5-day midtropospheric flow patterns for the South Pole: 1985-1989, Tellus, 44(B), 409-421, 1992.

Harris, J. M., and J. D. Kahl, A descriptive atmospheric transport climatology for the Mauna Loa Observatory, using clustered trajectories, J. Geophys. Res., 95, 13,651-13,667, 1990.

Horvath, H., Atmospheric light absorption - A review, Atmos. Environ., 27(A), 293-317, 1993.

Jennings, S. G., and R. G. Pinnick, Relationships between visible extinction, absorption and mass concentration of carbonaceous smokes, Atmos. Environ., 14, 1123-1129, 1980.

Joranger, E., and B. Ottar, Air pollution studies in the Norwegian Arctic, Geophys. Res. Lett., 11, 365-368, 1984.

Kiehl, J. T., and B. P. Briegleb, The relative roles of sulfate aerosols and greenhouse gases in climate forcing, Science, 260, 311-314, 1993.

Lin, C.-I., M. Baker, and R. J. Charlson, Absorption coefficient of atmospheric aerosol: A method for measurement, Appl. Opt., 12, 1356-1363, 1973

Liousse, C., H. Cachier, and S. G. Jennings, Optical and thermal measurements of black carbon aerosol content in different environments: Variation of the specific attenuation crosssection, sigma ( $\sigma$ ), Atmos. Environ., 27(A), 1203-1211, 1993.

Liousse, C., J. E. Penner, C. R. Molenkamp, J. J. Walton, H. Eddleman, I. Shult, and $\mathrm{H}$. Cachier, Modeling aerosols from biomass burning, paper presented at the Fifth International Conference on Carbonaceous Particles in the Atmosphere, Lawrence Berkeley Lab., Berkeley, Calif., 23-26 August, 1994.

Massey, D. M., T. K. Quakenbush, and B. A. Bodhaine, Condensation nuclei and aerosol scattering extinction measurements at Mauna Loa Observatory: 1974-1985, NOAA Data Rep. ERL ARL-14, 174 pp., Air Resour. Lab., Silver Spring, Md., 1987.

Mendonca, B. G., Local wind circulation on the slopes of Mauna Loa, J. Appl. Meteorol., 8, 533-541, 1969.
Merrill, J. T., M. Uematsu, and R. Bleck, Meteorological analysis of long range transport of mineral aerosols over the North Pacific, J. Geophys. Res., 94, 8584-8598, 1989.

Miller, J. M., A five-year climatology of back trajectories from the Mauna Loa Observatory, Hawaii, Atmos. Environ., 15, 1553-1558, 1981.

Murphy, M. E., and B. A. Bodhaine, The South Pole automatic condensation nuclei counter: Instrument details and five years of operations, NOAA Tech. Memo. ERL ARL-82, 88 pp., Air Resour. Lab., Silver Spring, Md., 1980a.

Murphy, M. E., and B. A. Bodhaine, The Barrow, Alaska automatic condensation nuclei counter and four wavelength nephelometer: Instrument details and four years of observations, NOAA Tech. Memo. ERL ARL-90, 101 pp., Air Resour. Lab., Silver Spring, Md., 1980 b.

Parungo, F., B. Bodhaine, and J. Bortniak, Seasonal variation in Antarctic aerosol, J. Aerosol Sci., 12, 491-504, 1981.

Pollak, L. W., and A. L. Metnieks, Intrinsic calibration of the photo-electric condensation nucleus counter model 1957 with convergent light-beam, Tech. Note 9, School of Cosmic Phys., Dublin Inst. for Adv. Study, 1960.

Quakenbush, T. K., and B. A. Bodhaine, Surface aerosols at the Barrow GMCC observatory: Data from 1976 through 1985, NOAA Data Rep. ERL ARL-10, 230 pp., Air Resour. Lab., Silver Spring, Md., 1986.

Rosen, H., A. D. A. Hansen, L. Gundel, and T. Novakov, Identification of the optically absorbing component in urban aerosols, Appl. Opt., 17, 3859-3861, 1978.

Rosen, H., T. Novakov, and B. A. Bodhaine, Soot in the Arctic, Atmos. Environ., 15, 1371-1374, 1981.

Sadler, M., R. J. Charlson, H. Rosen, and T. Novakov, An intercomparison of the integrating plate and the laser transmission methods for determination of aerosol absorption coefficients, Atmos. Environ., 15, 1265-1268, 1981.

Schnell, R.C., D. T. Kuniyuki, B. A. Bodhaine, and A. D. A. Hansen, The dust component of aerosol light absorption measured at Mauna Loa Observatory, paper presented at the Fiflh International Conference on Carbonaceous Particles in the Atmosphere, Lawrence Berkeley Lab., Berkeley, Calif., 23-26 August, 1994.

Shaw, G. E., Transport of Asian Desert aerosol to the Hawaiian islands, J. Appl. Meteorol., 19, 1254-1259, 1980.

Thielke, J. F., R. J. Charlson, J. W. Winter, N. C. Ahlquist, K. T. Whitby, R. B. Husar, and B. Y. H. Liu, Multiwavelength nephelometer measurements in Los Angeles smog aerosols, II. Correlation with size distributions, volume concentrations, J. Colloid Int. Sci., 39, 252-259, 1972.

Thermo Systems Incorporated (TSI), Model 3760 Condensation Nucleus Counter Instruction Manual, St. Paul, Minn., 1987.

Valero, F. P. J., and T. P. Ackerman, Arctic haze and the radiation balance, in Arctic Air Pollution, edited by B. Stonehouse, pp. 121-133, Cambridge, London, 1986.

van de Hulst, H. C., Light Scattering by Small Particles, John Wiley, New York, 1957.

B. A. Bodhaine, NOAA-CMDL R/E/CGl, 325 Broadway, Boulder, CO 80303. (email: bbodhaine@cmdl.noaa.gov)

(Received October 24, 1994; revised January 25, 1995; accepted February 6, 1995.) 